\title{
Preliminary Development of Radionuclides Release of Individual Dose Code Program for Radiation Monitoring Purposes
}

\author{
Jupiter Sitorus Pane $^{1 *}$, Pande Made Udiyani ${ }^{1}$, Muhammad Budi Setiawan, Surip Widodo ${ }^{1}$, I Putu Susila ${ }^{2}$ \\ ${ }^{1}$ Center for Nuclear Reactor Technology and Safety, BATAN, Kawasan Puspiptek Gd. 80, Tangerang Selatan 15310, Indonesia \\ ${ }^{2}$ Center for Nuclear Facility Engineering, BATAN, Kawasan Puspiptek Gd 80, Tangerang Selatan 15310, Indonesia.
}

\section{ARTICLE INFO}

\section{Article history:}

Received: 13 February 2021

Received in revised form: 07 June 2021

Accepted: 22 June 2021

\section{Keywords:}

Radiation

Release

Diffusion

Monitoring

Protecting

\begin{abstract}
A B S T R A C T
Environmental radiation monitoring is one of the important efforts in protecting society and the environment from radiation hazards, both natural and artificial. The presence of three nuclear research reactors and plans to build a nuclear power plant reactor prompted Indonesia to prepare a radiation monitoring system for safety and security (SPRKK). The goal of the study is to provide an appropriate method for developing radiation monitoring system to support the development of nuclear power plant in the near future. For this preliminary study, the author developed a code program using Gaussian distribution model approach for predicting radionuclide release and individual dose acceptancy by human being within 16 wind directions sectors and up to $50 \mathrm{~km}$ distance. The model includes estimation of source term from the nuclear installation, release of radionuclides source into air following Gaussian diffusion model, some of the release deposit to the land and entering human being through inhalation, direct external exposure, and resuspension, and predicted its accepted individual dose. This model has been widely used in various code program such as SimPact and PC-Cosyma. For this study, the model will be validated using SimPact code program. The model has been successfully developed with less than 5\% deviation. Further study will be done by evaluating the model with real measuring data from research reactor installation and prepare for interfacing with real time radiation data acquisition and monitoring as part of radiation monitoring system during normal and accident condition.
\end{abstract}

(C) 2021 Tri Dasa Mega. All rights reserved.

\section{INTRODUCTION}

Environmental radiation monitoring is one of the important efforts in protecting society and the environment from radiation hazards from nuclear

\footnotetext{
${ }^{*}$ Corresponding author. Tel./Fax.: +62 217562615

E-mail: jupiter pane@batan.go.id

DOI: $10.17146 / \mathrm{tdm} .2021 .23 .3 .6240$
}

installation. The presence of three nuclear research reactors and a plan to build a nuclear power plant (PLTN) have encouraged Indonesia to prepare a radiation monitoring system for safety and security (SPRKK). With this system, it will be easier for nuclear installation owners and the public to monitor and identify the presence of radiation anomaly in the environment around the nuclear 
installation for the purpose of emergency response. Indeed, the radiation from released radionuclides will affect the human being through immersion, deposition, and inhalation that represented as amount of radiation doses. For the purpose of medium- and long-term analysis, it is important to measure the radiation doses that enter human being through ingestion of irradiated plants and animals.

The purpose of this research paper is to develop a code program using theoretical model for radionuclides release that will be integrated to radiation acquisition and monitoring system for identifying emergency response. For the code program evaluation, the source term used in this simulation taken from SimPact Version 0.1, i.e. Tricastin Reactor France[1,2].

The model uses Gaussian diffusion approach to estimate the amount of radionuclides concentration in air and soil surface and to determine individual dose receipt by human being. The model also includes an estimation of source term release from the reactor installation. For this simulation, the author used source term from Tricastin Reactor France.If the real time radiation data and theoretical model estimation has shown results that exceeds the dose intervention limit, then emergency response steps must be taken in order to mitigate the radiological impact on the population and the environment.

The problem in this modelling is how to ensure the accuracy of the model to represent the release of radionuclides during an accident condition to a specific conditions of nuclear installation site in various locations in Indonesia.
For this initial stage, validation to a developed code program is done by comparing the result with manual calculation or using Excel spreadsheet, used in SimPact version 01. Furthermore, a comparative study will be carried out with various calculation results using other applicable commercial software such as PC-Cosyma implemented for research reactors as well as power reactors in various locations[3-6].

The next use of this code program is to integrate it with real time measurements in the Radiation Monitoring System which is simultaneously being developed at this time. With this integrated system, the operator can immediately be aware that a radiation anomaly occurred, and further emergency response are taken to protect the public and the environment from the radiation impact.

In this paper, we will describe in more detail the methodology that contains the models used for calculating individual dose from immersion, ground shine from deposition and inhalation of radionuclides, develop the code program and discuss the results to follow up with future work for future work and conclusion.

\section{METHODOLOGY}

\subsection{Modeling of Radionuclide Release from the Reactor}

The process of releasing radionuclide material into the environment and reaching humans during nuclear accident is depicted in a flow diagram as shown in Figure 1.

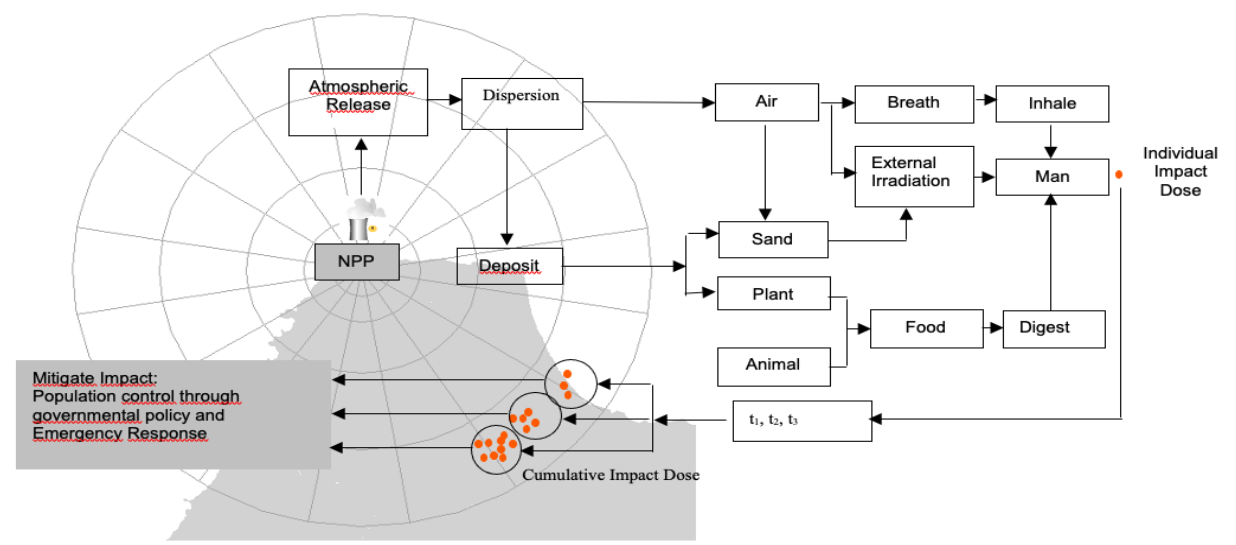

Fig.1. Diagram of the release of radionuclides into the environment.

The accident assumed that melting of nuclear fuel has occurred, some of which is released until it reaches the reactor containment as a last defense to confine radioactive material remains in the confinement and not released into the environment. For the licensing purposes, design requirement for leakage is only allowed for $0.1 \%$ per day[7].
The release of the radionuclides plume into the atmosphere will dilute the radionuclides concentration following wind direction and velocity as well as atmospheric stability. Some of these radionuclides will fall down as a deposition, some remain in the air forming radiation clouds that cause external exposure to humans and some are inhaled and enter their bodies. Radionuclides that 
undergo this deposition can also cause an external irradiation effect on humans and ingested through consuming animals and plants. Due to the radioactive nature of radionuclides, the impact to humans can be measured through individual dose receipt magnitude.

In accordance with Figure 1, the influx of radionuclide material into the human body is modelled diagrammatically as in Fig. 2. The model starts with source term model, dispersion and deposition that allow radionuclides available on air and soil, plant and animal that will reach humans by inhaling, ingesting, and immersing.

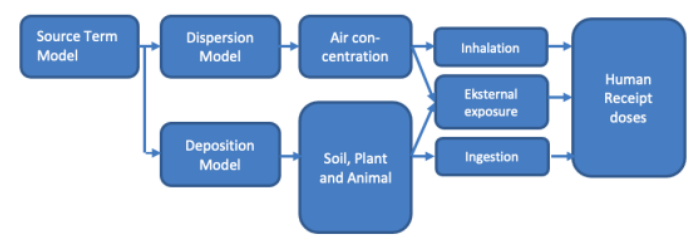

Fig. 2. A model diagram for screening calculation of the release of radionuclides to humans

\subsubsection{Source term calculation model}

In order to calculate the source term, the reactor core inventory is first determined using ORIGEN 2.1 software. In this study, the core inventory was taken from reference and study result from previous researches[8-14]. During an accident, a fraction of the inventory might be released through gap between fuel and assembly, reactor vessel at early phase, ex vessel, late early in vessel and containment depend on postulated accident conditions assumed, for example, station black out (SBO) that caused loss of coolant and at the same time an emergency cooling system did not function. The release fraction of each radionuclides group for each release can be seen at Table 1[14].

Table 1. Fraction of radionuclides release for PWR

\begin{tabular}{lcccc}
\hline Elements & $\begin{array}{l}\text { gap } \\
\text { release }\end{array}$ & $\begin{array}{l}\text { early in } \\
\text { vessel) }\end{array}$ & $\begin{array}{l}\text { ex- } \\
\text { vessel) }\end{array}$ & $\begin{array}{c}\text { late in } \\
\text { vessel }\end{array}$ \\
\hline $\mathrm{Kr}, \mathrm{Xe}$ & 0.05 & 0.95 & 0 & 0 \\
$\mathrm{I}, \mathrm{Br}$ & 0.05 & 0.35 & 0.25 & 0.1 \\
$\mathrm{Rb}, \mathrm{Cs}$ & 0.05 & 0.25 & 0.35 & 0.1 \\
$\mathrm{Te}, \mathrm{Se}$ & 0 & 0.05 & 0.25 & 0.005 \\
$\mathrm{Ba}, \mathrm{Sr}$ & 0 & 0.02 & 0.1 & 0 \\
$\mathrm{Co}, \mathrm{Mo}$, & 0 & 0.0025 & 0.0025 & 0 \\
$\mathrm{Tc}, \mathrm{Ru}, \mathrm{Rh}$ & & & & \\
$\mathrm{Y}, \mathrm{Zr}, \mathrm{Nd}$, & 0 & 0.0005 & 0.005 & 0 \\
$\mathrm{Eu}, \mathrm{Nb}$, & & & & \\
$\mathrm{Pm}, \mathrm{Pr}$, & & & & \\
$\mathrm{Sm}, \mathrm{Y}$, & & & & \\
$\mathrm{Cm}, \mathrm{Am}$, & & & & \\
$\mathrm{Ce}, \mathrm{Pu}, \mathrm{Np}$ & & & & \\
\hline
\end{tabular}

Furthermore, the radionuclides that reach the confinement are assumed to pass to the environment with a certain percentage of leakage (X) shown in Eq. 1[10]

$$
L(t)=\frac{B_{0} X}{2400} \cdot \frac{1}{\left(\lambda+\frac{X}{2400}\right)} \cdot\left[1-\exp \left[-\left(\lambda+\frac{X}{2400}\right) t\right]\right.
$$

where,

$$
\begin{array}{ll}
L(t) & : \text { leakage rate }(\mathrm{Bq} / \text { hour }) \\
B(t) & : \text { radionuclide concentration }\left(\mathrm{Bq} / \mathrm{m}^{3}\right) \\
X & : \text { leakage percentage per day } \\
l & : \text { half-life } \\
t & : \text { duration }
\end{array}
$$

\subsubsection{Model for calculating the dispersion of radionuclide releases to the air}

A number of radionuclides that escape from the containment will undergo dilution in the air so that the their radioactivity will continue to decrease according to the distance path. The mathematical model used follows the Gauss diffusion approach[15-21] as shown in Eq. 2.

$$
X(x, y, z)=\frac{Q_{o}}{2 \pi \sigma_{y} \sigma_{z} u} \exp -\left[\frac{y^{2}}{2 \sigma_{y}{ }^{2}}+\frac{\left(z-h_{e}\right)^{2}}{2 \sigma_{z}{ }^{2}}\right]
$$

where,

$X(x, y, z) \quad$ : concentration in air activities at point of $(x, y, z)\left(\mathrm{Bq} / \mathrm{m}^{3}\right)$

$x$ : distance from source (m)

$y$ : distance perpendicular to horizontal wind direction $(\mathrm{m})$

$z \quad:$ distance perpendicular to vertical wind direction $(\mathrm{m})$

$\sigma_{y} \quad:$ horizontal std deviation of Gauss distribution (m)

$\sigma_{z} \quad$ : vertical std deviation of Gauss distribution (m)

$\mathrm{Q}_{\text {o. }} \quad$ : release rate $(\mathrm{Bq} / \mathrm{m} 3)$

\subsubsection{Dose calculation model from external exposure or cloud}

The impact of radiation to human health[20, 21] and risk[22, 23] are indicated by dose parameter that figure out interaction between radiation with human tissue. Radionuclides that reach the ground surface can irradiate humans as clouds in which humans are immersed in it. The annual effective dose that reaches humans is calculated according to Eq. 3[15]. 
$E_{i m}=X(x, y, z) D F_{i m} O_{f}$

where,

$X_{(x, y, z)}$ : average annual concentration of radionuclide in air $\left(\mathrm{Bq} / \mathrm{m}^{3}\right)$

$D F_{\text {im }}$ : effective immersion dose coefficient (Sv/a per $\mathrm{Bq} / \mathrm{m})$

$O_{f} \quad$ : annual fraction of the hypothetical critical group exposed to this external dose.

\subsubsection{Deposition and resuspension calculation model}

A portion of the dispersed radionuclide material falls into the ground or is often called deposited which is modelled using Eq. 4[15],

$d_{i}=\left(V_{d}+V_{w}\right) * X_{(x, y, z)}$

where,

$d_{i}$ : average daily deposition rate (Bq. $\mathrm{m}^{-2}$. day)

$V_{d}:$ dry deposition coefficient (m/day)

$V_{w}$ : wet deposition coefficient (m/day)

\subsubsection{Model for calculating dose due to inhalation}

Radionuclides that reach the ground surface can be inhaled by human, causing internal irradiation. The annual effective dose due to inhalation that enters the human body is calculated using approach shown in Eq. 5[15],

$E_{\text {inh }}=X(x, y, z) R_{\text {inh }} D F_{\text {inh }}$

where,

$X(x, y, z)$ : concentration of radionuclides in air $(\mathrm{Bq} / \mathrm{m} 3)$

$R_{\text {inh }} \quad$ : rate of inhalation (m3 / year)

$D F_{\text {inh }}$ : inhalation dose coefficient $(\mathrm{Sv} / \mathrm{Bq})$

\subsubsection{Code program development}

The main purpose of this study is to develop code program that simulate the model to estimate the radiation dose of released radionuclides and reach humans through immersion, deposition, and inhalation. This code will be integrated into radiation monitoring system to become a comparison with the real time acquired radiation data. The code is designed to be able to estimate an individual dose at 16 wind direction sectors and 50 $\mathrm{km}$ radius. The population was assumed to be homogeneous at all sectors and radius.
In order to be able to evaluate the code program, the source term used for the simulation consists of 10 type of radionuclides i.e. H-3, C-14, Co-58, Co-60 Kr-85, I-131, I-133, Xe-133, Cs-134 and Cs-137. They were adopted from source term used for SimPact version 0.1, Tricastin Reactor France. The code program could be expanded to use more radionuclide types. Therefore, the flow chart diagram of the estimation was developed as shown in Figure 3 using the JAVA language. The program code is named DISPERSI-SPRRD while for research reactors will be named DISPERSISPRRR.

\section{RESULTS AND DISCUSSION}

The code program has been successfully developed to simulate the screening dose calculation of the radionuclides release from the source radionuclides, dispersed into the air and deposited into soil and reach human body through direct exposure from radiation cloud, ground shine, and inhalation. The model simulation can estimate individual dose at 16 wind sectors within $50 \mathrm{~km}$ radius.

In order to avoid false amount source term estimation and early detection of radionuclide release, the model must be integrated into stack monitor detector and the validation to the model can be performed by providing some detectors monitor at certain location surrounding the nuclear installation and perform measurements. The model simulation is also connected into meteorology stations in order to obtain real-time wind direction, velocity, and atmospheric stability. This setup will be part of model validation that might be implemented in one of BATAN's research reactor.

Figures 4 and 5 show the simulation result using DISPERSI-SPRRD which display the ambient radionuclides concentration and individual dose from radionuclides of $\mathrm{H}-3, \mathrm{C}-14, \mathrm{Co}-58, \mathrm{Co}-$ $60 \mathrm{Kr}-85, \mathrm{I}-131, \mathrm{I}-133$, Xe-133, Cs-134, and Cs137 at one wind direction (North) and wind velocity of $7.5 \mathrm{~m} / \mathrm{s}$ within $50 \mathrm{~km}$ radius, using source term data from Tricastin Reactor France at acertain wind direction i.e., North. Compared to the calculation result by SimPact version 0.1, this result is in good agreement. 


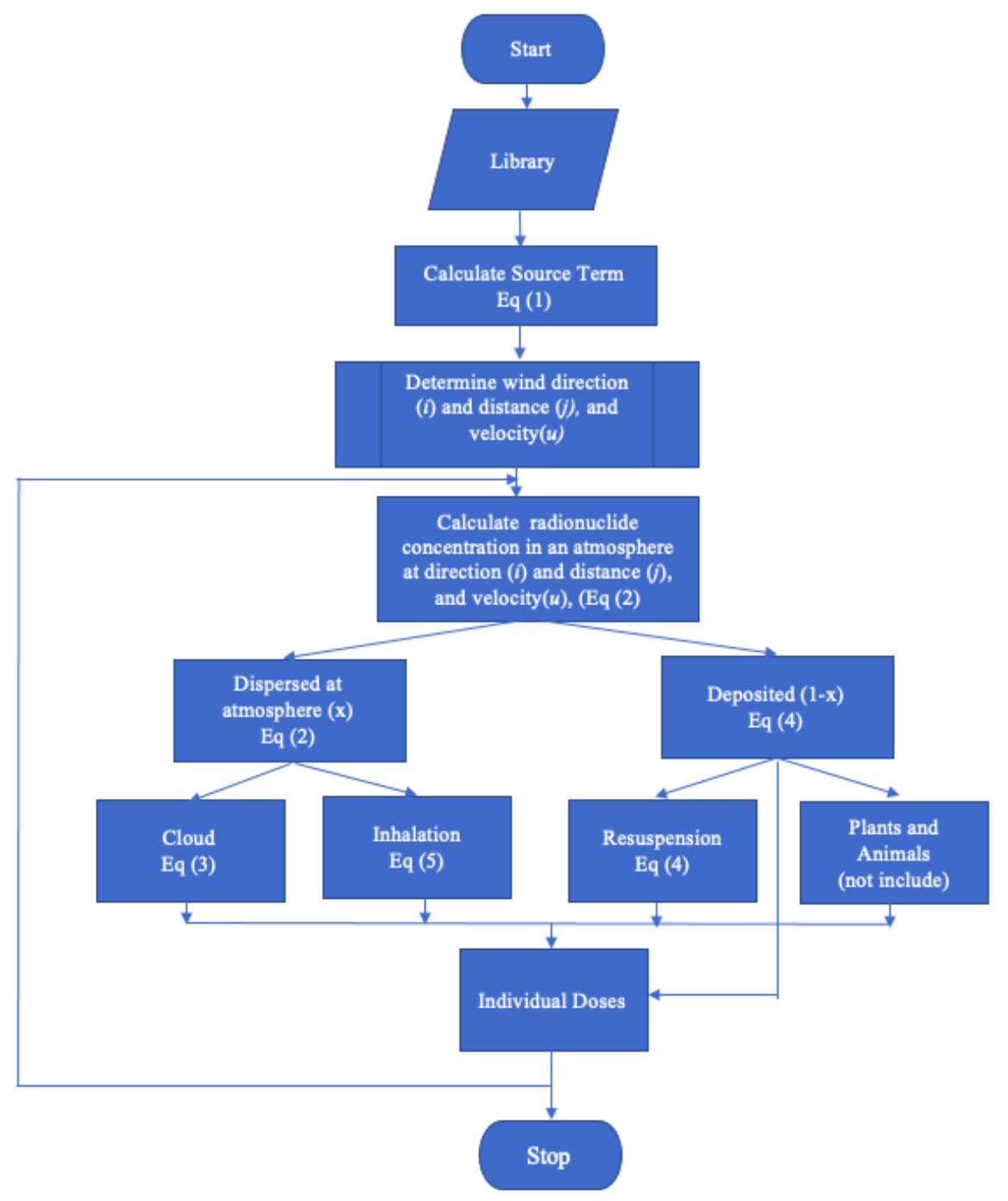

Fig. 3. Flow chart for calculating the individual dose of radionuclide released from a nuclear installation

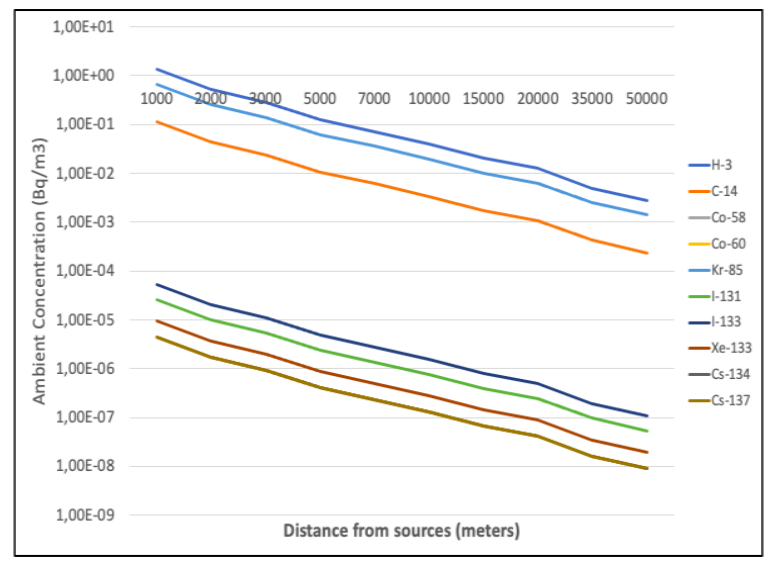

Fig. 4. Ambient Concentration of $\mathrm{H}-3, \mathrm{C}-14$, Co-58, Co-60 Kr-85, I-131, I-133, Xe-133, Cs134 and Cs-137 on air $50 \mathrm{Km}$ surround Nuclear Installation

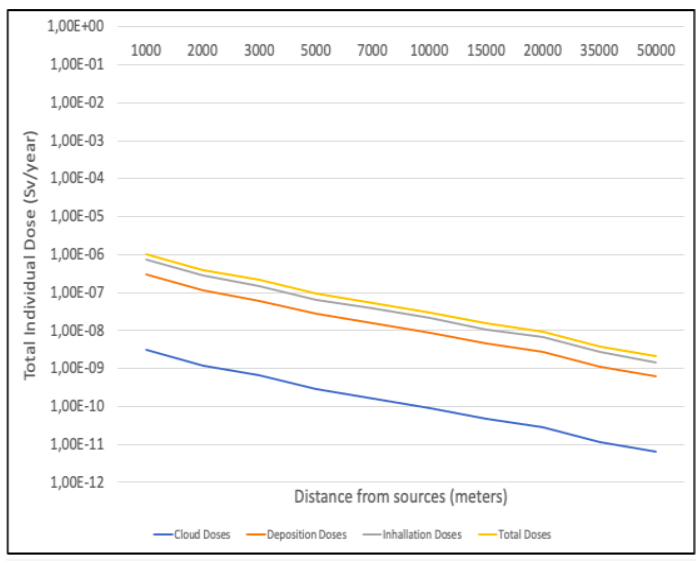

Fig. 5. The result of individual doses screening estimation from immersion in cloud, ground shine from deposition and inhalation

Likewise, for monitoring purposes, the accuracy of the calculations will depend on the results of real time measurements of wind speed,direction, and atmospheric stability. 
Therefore, the frequencies of acquiring data should be set up based on the frequency of real time meteorology data in order to follow the changing on wind direction and velocity. It can be per hour or certain minutes, such as 10 or 20 minutes.

The number of radionuclides contributed to the estimation can be flexible depend on how accurate we want to achieve. It can be single or multiple radionuclides. Currently, this calculation uses 10 types of radionuclides, but if needed, the numbers can be added for better radiation dose estimation.

This code program can also be applied to model the release from research reactor accident.

\section{CONCLUSION}

A preliminary study on modelling the radiation exposure to the environment has been developed for monitoring and screening purposes. The code program for such model has been developed and can potentially be integrated with the current development of real time radiation monitoring system. The code program has been run and evaluated, withthe results showed a similar value compared with named SimPact version 0.1 with less than $5 \%$ differences. In order to get real validation to the model, some of field experiment measurement must be set up in one of BATAN's research reactor.

\section{ACKNOWLEDGMENT}

The works are conducted under the government research and funding managed by Center for Nuclear Reactor Technology and Safety (PTKRN), BATAN, for the year of 2020. It is also partially supported by 2018-2021 CRP-IAEA (CRP code- I31029).

\section{AUTHOR CONTRIBUTION}

Jupiter S Pane, Pande Made Udiyani and Muhammad Budi Setiawan equally contributed as the main contributors of this paper. All authors read and approved the final version of the paper.

\section{REFERENCES}

1. Spadaro, V. 2002, SimPact version 0.1, The Official Version of SimPacts (Version 1.0), International Atomic Energy Agency, Vienna, Austria.

2. Carlos E. Velasquez, Fidéllis B.G. L. e Estanislau, Antonella L. Costa, Claubia Pereira, Assessment of the French Nuclear Energy System - A Case Study, Energy Strategy Reviews, Volume 30, 2020, 100513,
ISSN2211-467X, https://doi.org/10.1016/j.esr. 2020.100513.

3. PM. Udiyani, S. Kuntjoro, M.B. Setiawan, I. Husnayani, Estimation of Radioactivity Impact for RDE Based on HTR-10 Hypthetical Accident- a Case Study. in: International Symposium of Emerging Nuclear Technology and Engineering Novelty. IOP Conf. Series: Journal of Physics: Conf. Series 1198, 022037, 2019.

4. Udiyani P.M., Husnayani I., Deswandri, Sunaryo GR. Analysis of Radiation Safety for Small Modullar Reactor (SMR) on PWR 100 MWe type in: International Symposium of Emerging Nuclear Technology and Engineering Novelty. IOP Conf. Series: Journal of Physics: Conf. Series 962 (2018) 012035.

5. P.M. Udiyani, S. Kuntjoro, S. Widodo, 2016, A Backward Method to Estimate the Dai-ichi Reactor Core Damage Using Radiation Exposure in the Environment. Atom Indonesia. 2016. 42(2): 63-70.

6. PM Udiyani, S Kuntjoro, GR Sunaryo, H Susiati, 2018, 20192020, Atmospheric dispersion Analysis for Expected Radiation dose due to Normal Operation of RSG-GAS and RDE Reactors, Atom Indonesia. 2018. 43(3): 115-121.

7. Ji SukKim, Man CheolKim. Consistency Issues in Quantitative Safety Goals of Nuclear Power Plants in Korea, Journal of Nuclear Engineering and Technology. 2019. 51(7): 1758-1764.

8. Ned Xoubi. Source Term Derivation and Radioactive Release Evaluation for JRTR Research Reactor under Severe Accident, Journal Science and Technology of Nuclear Installation, Volume 2020 Article ID 1868965.

9. Ardani. Analisis Aktivitas Sumber Radiasi Dan Intensitas Sinar Gamma Di Teras Reaktor PWR 1000 MWe. Jurnal Teknologi Reaktor Nuklir Tri Dasa Mega. 2010. 12(3): 67-74,

10. Sri Kuntjoro, Pande Made Udiyan, Analisis Inventori Reaktor Daya Eksperimental Jenis Reaktor Gas Temperatur Tinggi. Urania Jurnal Ilmiah Daur Bahan Bakar Nuklir. 2016 22(1): 53-64.

11. Terada, H, Haruyasu Nagai, Katsunori Tsuduki, Akiko Furuno, Masanao Kadowaki 
12. Toyokazu Kakefuda. Refinement of Source Term and Atmospheric Dispersion Simulations of Radionuclides During the Fukushima Daiichi Nuclear Power Station Accident. Journal of Environmental Radioactivity, 2020. 213. 106104.

13. Zhao Y., Zhang L.,Tong J. Development of Rapid Atmospheric Source Term Estimation System for AP 1000 Nuclear Power Plant. Progress in Nuclear Energy. 2015. 81: 264275.

14. Udiyani PM. and Setiawan M.B., Source Term Assessment for 100 MWe Pressurerized Water Reactor. Journal of Nuclear Reactor Technology Tri Dasa Mega. 2020. 22 (2): 6167.

15. Herranza LE, Hasteb T, Kärkeläc T. Recent Advances in the Source Term Area within the SARNET European Severe Accident Research Network. Nuclear Engineering and Design. 2015. 288: 56-74.

16. Mahmoud Pashazadeh, A., Aghajani, M., Nabipour, I., \& Assadi, M. (2014). Annual Effective Dose from Environmental Gamma Radiation in Bushehr City. Journal of Environmental Health Science \& Engineering, 12(1): $1-4$.

17. Róbert Mészáros \& Ádám Leelőssy \& Csilla Vincze \& Mihály Szücs \& Tibor Kovács \& István Lagzi. Estimation of the Dispersion of an Accidental Release of Radionuclides and Toxic Materials Based on Weather Type Classification, Theor Appl Climato. 2012. 107: 375-387.

18. Oura, Masamichi; Ohba, Ryohji; Robins, Alan; Kato, Shinsuke. 2018. "Validation Study for an Atmospheric Dispersion Model, Using Effective Source Heights Determined from Wind Tunnel Experiments in Nuclear Safety Analysis" Atmosphere 9(3): 111.

19. Pirouzmand A., Dehghani P., Hadad K., Nematollahi, M. Dose Assessment of Radionuclides Dispersion from Bushehr Nuclear Power Plant Stack under Normal Operation and Accident Conditions, International Journal of Hydrogen Energy. 2015. 40: 15198-15205.

20. Yangmo Z, Jianghua G, Nie N, Youhua Z. Simulation and Dose Analysis of a Hypothetical Accident in Sanmen Nuclear Power Plant. Annals of Nuclear Energy. 2014. 65:207-213.

21. Barakat M S, Bashter K II, Ibrahim, Tawfik F S, Nagla, TF. Health Impacts of Routine Gaseous Releases from Nuclear Facilities.
European Academic Research. 2016. 4(9): 7795-7813.

22. Aliyu A.S., Ramli A.T., Saleh M.A., Assessment of Potential Human Health and Environmental Impacts of a Nuclear Power Plant (NPP) Based on Atmospheric Dispersion Nodeling, Atmósfera. 2015. 28: 13-26.

23. V. Ragaišis, P. Poškas, V. Šimonis, A. Šmaižys, R. Kilda, D. Grigaliūnienè, The Environmental Impact Assessment Process for Nuclear Facilities: A Review of the Lithuanian Practice and Experience. Progress in Nuclear Energy, 2014. 73: 129-139.

24. Vandenhovea H., et al. Predicting the Environmental Risks of Radioactive Discharges from Belgian Nuclear Power Plants. Journal of Environmental Radioactivity. 2013. 126: 61-76. 
